\title{
COMMUNITY PERSPECTIVE
}

\section{Medical urologists... no longer an oxymoron}

\author{
Richard Casey, MD, FRCS
}

Community Urologist, Oakville, ON, Canada

Cite as: Can Urol Assoc J 2019;13(2):71-2. http://dx.doi.org/10.5489/cuai.5820

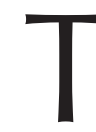

he bulk of what community urologists see could be called "medical urology." We work through large numbers of patients each week - a week punctuated with stones, retention, and hematuria calls from our local hospital's emergency room. We have surgical interests as well and they eventually define our practice. My partner is a stone guy, another department member loves lap kidneys, and I actually like male incontinence. It is difficult for me to justify a broad range of surgical skills when my colleagues can do a better job. This applies to advanced surgical skills only, as you can only be so skilled at circumcisions, vasectomies, and hydroceles. There is good published data that suggests that high-volume surgeons have superior outcomes. This does not mean that low-volume guys don't as well well, some don't and we know that empirically.

Where am I going with this? I'II use my experience as an example.

In 1984, I started my practice in Oakville, Ontario. Patrick Walsh had just published his treatise on prostate cancer and nerve-sparing. Prior to this, radical prostatectomies were nightmarish procedures. I had just spent years at Toronto General Hospital learning the transpubic route to the radical prostatectomy. The only nerves spared were our own if we were able to finish in under three hours and not have to arrange for an ICU bed. Walsh's attention to detail and the introduction of prostate-specific antigen slowly changed this procedure, the patient mix, and our acceptance of the procedure.

With a little hustle, I was able to convince a number of local urologists that I could

handle the work, and by 1992, I was logging about 75 radical prostatectomies a year. It was a routine procedure, rarely requiring blood, with patients staying in hospital for two nights at most. My partner and I heard that Ralph Clayman had tried a few using a laparoscope and thought he was nuts. Fast-forward 15 years and few new grads are taught the classic Walsh prostatectomy. I had been too busy working and too narrow-minded to embrace the new technology. When Bobby Shaygean opened his robot for business, we decided to send everyone that way. We could not compete with his results and we owed it to our patients.
Specialities will evolve - as evidenced by our interventional radiology colleagues - usually to a better place. We've all witnessed the effect of technology on our practices and seen what it can do to others. Should cardiac surgeons have taken the stent technology and used it themselves? The introduction of new technology makes it harder for surgical specialists to keep up the broadening skillset available. I was trained before laparoscopy and was able to learn handassisted kidneys before we hired a trained laparoscopy surgeon. Not knowing what type of intervention their patient may need, family physicians refer their patients to specialists they know or like. It is then up to us to sort out what, if any, intervention is required.

There are some skills that are not particularly technologydependant. Treating benign prostatic hyperplasia, erectile dysfunction, urinary tract infections, Peyronie's disease and, dare I say it, pelvic pain, require patience, clinical skills, and little technology. Those of you who are over 45 , think about how your treatment of these conditions has evolved from the first few years of practice.

Another example is castrate-resistant prostate cancer (CRPC). Only about a third of practicing urologists treat CRPC, which I find perplexing. I've held on to these patients, learned about second-line therapies, and participated in clinical trials. I think we can do as good a job as the medical oncologists. These patients are the soul of our practice!

Medical skills, dare I say it, are easier to learn than surgical procedures. A larger portion of urology is now medically based with non-surgical solutions. In 1985, when I started practice, we performed about 200 transurethral resections of the prostate (TURPs) a year, usually for symptomatic relief. In 2015, 90\% of the transurethral resections I perform are in urinary retention. It is rare to recommend surgery without evidence of medical failure or side effect issues with standard therapies.

Those of us in community practice sift through dozens of patients a week to find surgical candidates and this proportion is growing. Imagine a trained urologist who decides to only focus on the medical side of the speciality. Instead of being left behind with the forward rush of technology, concentrating on the non-surgical options would allow him/her to continue to treat a majority of the GU population - something many 
new family physicians are not doing — and send those who will need intervention to surgical colleagues.

While a locum in New Zealand, I was asked to assist with triage to the urology clinic at the hospital at which I was working. Family physicians would fill out requests for consultations and the surgical staff would review and either give them an appointment ("Assess hard prostate with PSA of 25") or not ("Testicular pain for three years, normal ultrasound"). This resulted in clinics where a majority of patients would require our surgical expertise! While this isn't possible in Canada, an intermediate step might work just as well.

Medical urology...for those of us who've practiced for a while, it's what we tolerate to find surgical cases. Could we learn to enjoy this part of the practice? More importantly, by spending more time with the non-surgical patients and focusing on this aspect of urology, would we do a better job?

In Table 1, I've listed a preliminary set of qualifications for a medical urologist and conditions for practice. I've also included what areas and minor procedures might accompany the designation. A number of pre-surgical diagnostic procedures are included. A close relationship with surgical groups would be necessary, as it will take confidence in the results to commit to surgical intervention by another surgeon. I believe this can work, as evidenced by my experience in New Zealand.

This type of medical urology practice would require limited hospital resources and no general anesthetic time. In addition, medical urologists could participate in the on-call schedule if they worked closely with the surgical group. Many older urologists allow their practices to evolve to a similar skill set, and the trick is to support your local, younger staff with all the larger surgical cases. If my discussions with younger urologists are accurate, this has not historically been the case.

I believe medical urology will evolve and it would be helpful to develop a consensus to see if there might be a need to 'stream' medical urologists later in their training. The support of the Canadian Urological Association is likely to put more structure in the training and practice and allow future medical urologists to become an integral part of hospital staffs.

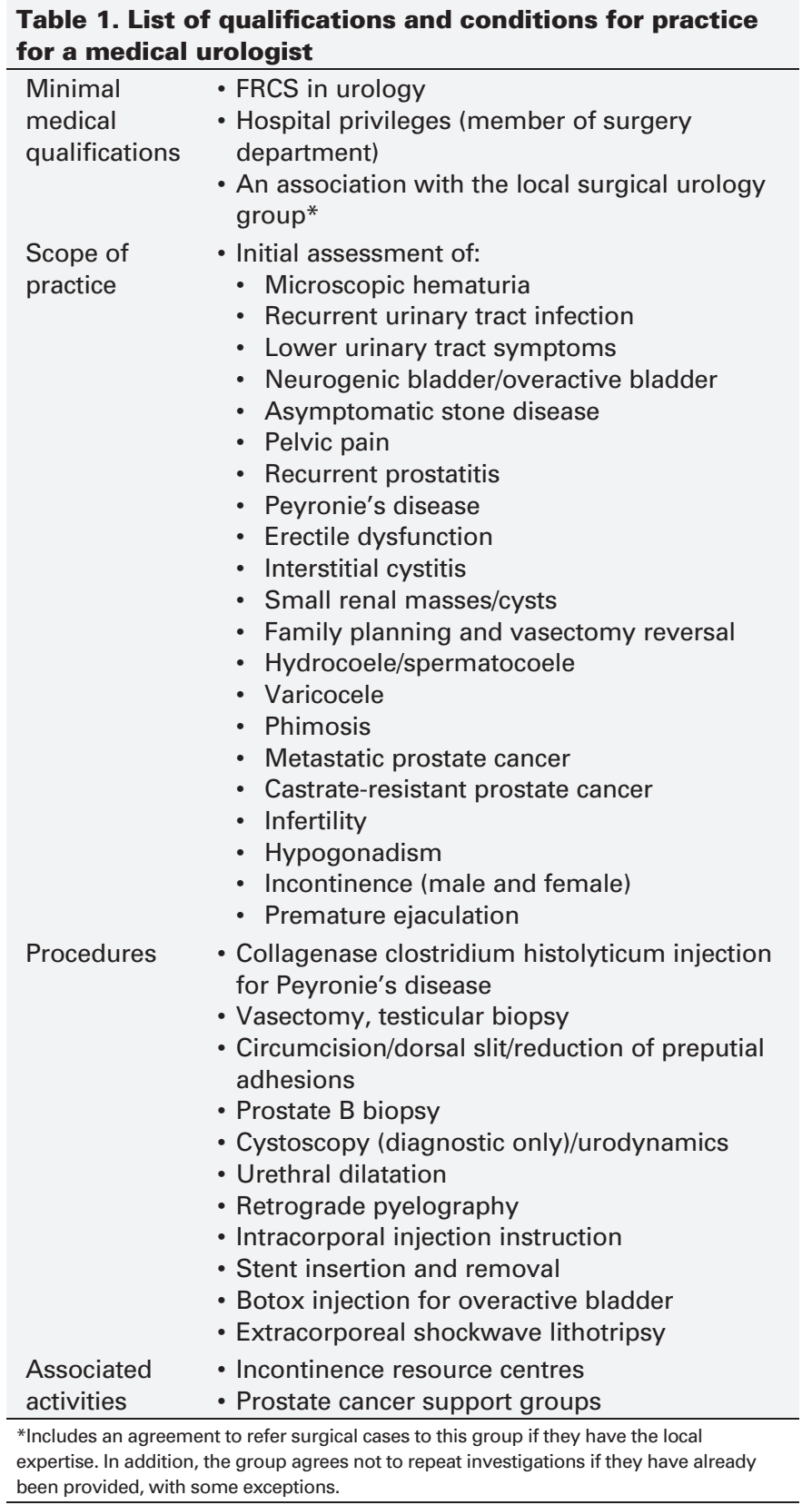

\section{for a medical urologist}

\begin{tabular}{|c|c|}
\hline $\begin{array}{l}\text { Minimal } \\
\text { medical } \\
\text { qualifications }\end{array}$ & $\begin{array}{l}\text { - FRCS in urology } \\
\text { - Hospital privileges (member of surgery } \\
\text { department) } \\
\text { - An association with the local surgical urology } \\
\text { group* }\end{array}$ \\
\hline $\begin{array}{l}\text { Scope of } \\
\text { practice }\end{array}$ & $\begin{array}{l}\text { - Initial assessment of: } \\
\text { - Microscopic hematuria } \\
\text { - Recurrent urinary tract infection } \\
\text { - Nower urinary tract symptoms } \\
\text { - Asymptomatic stone disease } \\
\text { - Pelvic pain } \\
\text { - Recurrent prostatitis } \\
\text { - Peyronie's disease } \\
\text { - Erectile dysfunction } \\
\text { - Interstitial cystitis } \\
\text { - Small renal masses/cysts } \\
\text { - Family planning and vasectomy reversal } \\
\text { - Hydrocoele/spermatocoele } \\
\text { - Varicocele } \\
\text { - Phimosis } \\
\text { - Metastatic prostate cancer } \\
\text { - Castrate-resistant prostate cancer } \\
\text { - Infertility } \\
\text { - Hypogonadism } \\
\text { - Incontinence (male and female) }\end{array}$ \\
\hline Procedures & $\begin{array}{l}\text { - Collagenase clostridium histolyticum injection } \\
\text { for Peyronie's disease } \\
\text { - Vasectomy, testicular biopsy } \\
\text { - Circumcision/dorsal slit/reduction of preputial } \\
\text { adhesions } \\
\text { - Prostate B biopsy } \\
\text { - Cystoscopy (diagnostic only)/urodynamics } \\
\text { - Urethral dilatation } \\
\text { - Retrograde pyelography } \\
\text { - Intracorporal injection instruction } \\
\text { - Stent insertion and removal } \\
\text { - Botox injection for overactive bladder } \\
\text { - Extracorporeal shockwave lithotripsy }\end{array}$ \\
\hline $\begin{array}{l}\text { Associated } \\
\text { activities }\end{array}$ & $\begin{array}{l}\text { - Incontinence resource centres } \\
\text { - Prostate cancer support groups }\end{array}$ \\
\hline
\end{tabular}

Correspondence: Dr. Richard Casey, Community Urologist, Oakville, 0N, Canada; drrcasey@gmail.com 